ISSN electrónico: $1885-5210$

DOI:https://doi.org/10.14201/rmc20211717175

\title{
LA VEJEZ Y EL AMOR NEGADO
}

\section{Old age and love denied}

\author{
Alejandra SALDARRIAGA CANTILLO \\ Universidad del Valle. Cali (Colombia). \\ Correo electrónico: alejandrasaldarriaga20@yahoo.com
}

Recibido: 4 de diciembre de 2020

Aceptado: 2 de enero de 2021

\section{Resumen}

Consume mi corazón; enfermo de deseo $y$ atado a un animal moribundo que no sabe lo que es; y hazme parte de la ilusión de la eternidad.

W.B. Yeats.

El amor y la sexualidad son áreas de la medicina relativamente inexploradas, en las que pueden primar los mitos y los tabúes por encima de la empatía. Esto aplica para todas las etapas de la vida, principalmente para la vejez. La expresión de la sexualidad en los adultos mayores es ignorada, por no decir que muchas veces es negada, rechazada y entorpecida por la sociedad.

Existe un nexo indisoluble entre la historia, la medicina y la literatura, que nos permite analizar los mitos y prejuicios relacionados con la vejez, el sexo y el amor. Por medio de algunos ejemplos literarios hago una reflexión acerca de esta temática, teniendo en cuenta el fenómeno de envejecimiento poblacional mundial.

Superar estos prejuicios puede liberar a nuestros adultos mayores del sufrimiento innecesario de no poder amar y no poder ser amados. Como sociedad tenemos el deber de comprender y trabajar para que el amor en la vejez no sea una realidad negada.

Palabras clave: vejez; amor; sexualidad; poesía; literatura. 


\section{Abstract}

Consume my heart away; sick with desire And fastened to a dying animal It knows not what it is; and gather me Into the artifice of eternity.

Love and sexuality are relatively unexplored areas of medicine, where myths and taboos may prevail over empathy. This applies to all stages of life, mainly for old age. The expression of sexuality in older adults is ignored, not to say that it is often denied, rejected and hindered by society.

There is an indissoluble nexus between history, medicine and literature, which allows us to analyze the myths and prejudices related to old age, sex and love. Through some literary examples I reflect on this issue, taking into account the phenomenon of world population aging.

Overcoming these prejudices can free our older adults from the unnecessary suffering of not being able to love and not being able to be loved. As a society we have the duty to understand and work so that love in old age is not a denied reality.

Keywords: old age; love; sexuality; poetry; literature.

Desde hace algunas décadas, se está generando un proceso de transición demográfica mundial caracterizado por el aumento de la expectativa de vida al nacer y el aumento representativo de la población de adultos mayores ${ }^{1}$. Este fenómeno social obliga a cuestionarnos sobre la "cultura de la vejez», donde se incluye la esfera afectiva y sexual ${ }^{2}$.

En las sociedades antiguas, alcanzar edades avanzadas significaba un privilegio que no podía lograrse sin la ayuda de los dioses; por tanto, la longevidad equivalía a una recompensa divina dispensada para los justos ${ }^{3}$.

En diferentes contextos culturales ha existido la tendencia a sobrevalorar atributos físicos transitorios como la juventud, la belleza y la fuerza, opacando simultáneamente el encanto de la edad madura ${ }^{4}$. La dificultad para afrontar algo tan natural y deseable como el amor en la vejez ha llevado a la falacia de convertir al adulto mayor en un falso joven; como también ha llevado al extremo contrario, en el que es considerado como un ser asexuado.

Muchos adultos mayores interiorizan esta norma no escrita del rechazo al amor y al sexo, escondiendo sus sentimientos y sus deseos sexuales. Esto se refuerza con la infantilización por parte de la familia, las dificultades locativas para lograr un ambiente íntimo, las dificultades económicas, la discapacidad y la pérdida de autonomía 5 .

El amor es una de las emociones humanas más deseables e intensas que involucra la intimidad, la pasión y el compromiso. Los adultos mayores experimentan el amor de diferentes maneras; sin embargo, el vínculo emocional en la vejez es tan importante como en cualquier otra etapa de la vida6.

Como se describe a continuación con los siguientes ejemplos literarios, con frecuencia se asume una miseria erótica en los adultos mayores. En la novela Hombre Lento de J.M. Coetzee el personaje principal es Paul Rayment, un fotógrafo de 60 años quien sufre la amputación de una pierna en un accidente de tránsito. Se describe el estado de indefensión de un hombre mayor aferrado testarudamente a sus principios, al igual que ilustra el deterioro de su estado de ánimo al perder su autonomía. En estas circunstancias, Paul se deja arrastrar por un ímpetu amoroso hacia su enfermera. En esta obra se reflexiona sobre la vejez, la discapacidad, y las necesidades de un corazón en hibernación que despierta para continuar anhelando placer y felicidad? 
En el libro El amor en los tiempos del cólera del escritor Gabriel García Márquez se describe una historia de amor perenne y los diferentes escenarios relacionados con la aversión al amor en la vejez. Ofelia, hija de Fermina Daza, al enterarse que su madre está siendo cortejada por Florentino Ariza realiza la siguiente condena: «El amor es ridículo a nuestra edad, pero a la edad de ustedes es una cochinada». En esta afirmación se evidencia una de las múltiples formas en que la sociedad anula el derecho al goce corporal y afectivo en el adulto mayor. Sin embargo, Fermina Daza se rebela contra este mandato social, empoderándose de sus decisiones afectivas: "Ahora mismo te vas de esta casa, y te juro por los restos de mi madre que no la volverás a pisar mientras yo esté viva» ${ }^{8}$.

Raúl Gómez Jattin realiza una descripción autobiográfica de su cuerpo en decadencia, deteriorado por el paso de los años y la mendicidad. Relata la angustia de un alma enamorada que está atrapada en un cuerpo envejecido y condenada a la soledad. La poesía resulta ser la única compañía posible y la única manera de expresarse en un mundo adverso:

\author{
De lo que soy ${ }^{(9)}$ \\ En este cuerpo \\ En el cual la vida ya anochece \\ Vivo yo \\ Vientre blando y cabeza calva \\ Pocos dientes \\ $Y$ yo adentro \\ Como un condenado \\ Estoy adentro y estoy enamorado \\ $Y$ estoy viejo \\ Descifro mi dolor con la poesía \\ $Y$ el resultado es especialmente doloroso \\ Voces que anuncian: ahí vienen tus angustias \\ Voces quebradas: pasaron ya tus días. \\ La poesía es la única compañera \\ Acostúmbrate a tus cuchillos, \\ Que es la única.
}

Constantino Cavafis describe las añoranzas de un hombre mayor por los años de juventud y sus deliciosas virtudes. Se reprocha a si mismo por no haber vivido lo que quería cuando su cuerpo le permitía hacerlo. Hay un notorio contraste entre las dos etapas de la vida, sobrevaluando la juventud como sinónimo de fuerza, elocuencia y belleza; y calificando despectivamente a la vejez como una época miserable caracterizada por la enfermedad y el cansancio:

\section{El Viejo ${ }^{(10)}$}

En una esquina del café sonoro de murmullos confusos

un anciano sentado se inclina sobre la mesa, leyendo un periódico, sin compañía.

$Y$ en el ocaso de su miserable senectud piensa cuán poco gozó en los años cuando tuvo la fuerza y el verbo y la belleza. Sabe que está muy viejo, y lo siente, y lo ve. $Y$, sin embargo, le parece que la juventud fue ayer. iCorto intervalo, corto!

$Y$ piensa en qué forma lo embaucó la prudencia, cómo de ella se fio y qué locura cuando la engañadora le decía: "Mañana. Tienes todo tu tiempo».

Se acuerda de los impulsos que detuvo y cuántas delicias sacrificó. Ocasiones perdidas que burla ahora su prudencia insensata. ...A fuerza de rumiar pensamientos y recuerdos el vértigo lo invade. Y se duerme inclinado sobre la mesa del café.

Piedad Bonnett habla sobre los dilemas que se plantea una mujer de edad madura que aún no ha encontrado el amor de pareja. Reflexiona acerca de la vergüenza y el temor de envejecer en soledad, anticipando que el amor no es un patrimonio merecido para las personas mayores:

\section{Ahora que ya no soy más joven ${ }^{(11)}$}

Ahora que ya remonto la mitad del camino de mi vida,

yo que siempre me apené de las gentes mayores, yo, que soy eterna pues he muerto cien veces, de tedio, de agonía,

y que alargo mis brazos al sol en las mañanas y me arrullo 
en las noches y me canto canciones para espantar el miedo,

¿qué haré con esta sombra que comienza a vestirme

y a despojarme sin remordimientos? ¿Qué haré con el confuso y turbio río que no encuentra su mar,

con tanto día y tanto aniversario, con tanta juventud a las espaldas,

si aún no he nacido, si aún hoy me cabe un mundo entero en el costado izquierdo? ¿Qué hacer ahora que ya no soy más joven si todavía no te he conocido?

La vejez no sólo implica declives. También es la época que se ha recopilado la sabiduría, la experiencia y la fortaleza. Se habla de ella como el otoño de la vida, por la analogía con las estaciones del año y la sucesión de los ciclos de la naturaleza. Basta observar a lo largo del año los cambios del paisaje en la montaña y en la llanura, en los prados, los valles y los bosques, en los árboles y las plantas. Hay una gran semejanza entre los biorritmos del hombre y los ciclos de la naturaleza, de la cual él mismo forma parte.

El curso de la vida lo expresó Amado Nervo en su poema titulado En Paz. Relatado desde una perspectiva sabia, madura y serena, en este escrito se expresa la gratitud de un hombre mayor por la vida que ha construido. Reconoce la importancia del amor al ser dado y al ser recibido, logrando la paz en su balance final.

\section{«En paz» ${ }^{(12)}$}

Muy cerca de mi ocaso, yo te bendigo, Vida, porque nunca me diste ni esperanza fallida, ni trabajos injustos, ni pena inmerecida; porque veo al final de mi rudo camino que yo fui el arquitecto de mi propio destino; que si extraje las mieles o la hiel de las cosas, fue porque en ellas puse hiel o mieles sabrosas: cuando planté rosales, coseché siempre rosas. Cierto, a mis lozanías va a seguir el invierno: imás tú no me dijiste que mayo fuese eterno! Hallé sin duda largas las noches de mis penas;
Mas no me prometiste tan sólo noches buenas; y en cambio tuve algunas santamente serenas..

Amé, fui amado, el sol acarició mi faz.

¡Vida, nada me debes! iVida, estamos en paz!

En la palabra escrita ha permitido describir los diferentes patrones sociales de comportamiento frente a la vejez y la dificultades impuestas a la hora de amar. Ver en una persona «vieja» a alguien degradado que se hunde en un embotamiento de pobreza y soledad; alguien incluso, enfermo y depravado, es «El crimen de nuestra sociedad $»^{13}$. De esta manera, entendemos que la vejez es una circunstancia vital fuertemente relacionada con el entorno donde se exige asumir el cuerpo, la sexualidad, la vida y la muerte desde otra perspectiva.

También se debe considerar la narrativa como una herramienta de formación académica, que nos permite entender las áreas ignoradas de la medicina y sociología, como lo es el amor en la vejez. Fernando Navarro mencionaba: «No es nada raro que, en el ejercicio de su profesión, el médico busque los aspectos más profundos de la enfermedad, el dolor, el sufrimiento, la locura y la muerte, los sentimientos o sensaciones más íntimos. En esta búsqueda, los libros de texto son de escasa utilidad: es necesario acudir a la literatura universal ${ }^{14}$.

Como comentario final quisiera generar un ambiente de reflexión sobre nuestro deber social para lograr que el amor en la vejez no sea una realidad negada. Superar estos prejuicios es el camino para liberar a nuestros adultos mayores del sufrimiento innecesario de no poder amar.

\section{Referencias}

1. Garcia EV. Research: A priority for the decade of healthy aging. Colomb Med (Cali). 2019; 50(2): 50-1.

2. Štulhofer A, Hinchliff S, Jurin T, Hald GM, Træen B. Successful Aging and Changes in Sexual Interest and Enjoyment Among Older European Men and Women. J Sex Med. 2018;15(10):1393-402.

3. Moog PF, Schäfer D. Joannes stobaios, «on old age»: An important source for the history of gerontology. J Am Geriatr Soc. 2008;56(2):354-8. 


\section{LA VEJEZ Y EL AMOR NEGADO}

ALEJANDRA SALDARRIAGA CANTILLO

4. Moreno-Toledo Á. Viejismo (ageism). Percepciones de la población acerca de la tercera edad: estereotipos, actitudes e implicaciones sociales. Poiésis. 2010; 10(19).

5. Kleinspehn-Ammerlahn A, Kotter-Grühn D, Smith J. Self-perceptions of aging: Do subjective age and satisfaction with aging change during old age? J Gerontol B Psychol Sci Soc Sci. 2008;63(6):377-85.

6. Scheidt RJ, Bosch J. Love, sex, and aging. Gerontologist. 2014;54(4):714-7.

7. Coetzee J.M. Hombre Lento. Barcelona: Random House; 2006.

8. García Márquez G. El amor en los tiempos del cólera. Bogotá: La Oveja Negra; 1985.
9. Gómez Jattin R. Amanecer en el Valle Del Sinú: Antología Poética. México: Fondo de Cultura Económica; 2004.

10. Cavafis C. Poesía completa Madrid: Alianza; 1994.

11. Bonnett P. Lo demás es silencio: Antología poética. Madrid: Hiperión; 2003.

12. Reyes A. Antología de Amado Nervo: poesía y prosa. México: Conaculta: 2001.

13. De Beavouir S. La vejez. Barcelona: Debolsillo. 2013.

14. Navarro F. La peste (1947). Diario Médico [Internet]. 2006. [Consultado el 8 de septiembre de 2020]. 